\title{
Relating photosynthetic pigments and in vivo optical density spectra to irradiance for the Florida red-tide dinoflagellate Gymnodinium breve
}

\author{
David F. Millie ${ }^{1,2}$, Gary J. Kirkpatrick ${ }^{3}$, Bryan T. Vinyard ${ }^{1}$ \\ ${ }^{1}$ U.S. Department of Agriculture, Agricultural Research Service, Southern Regional Research Center, PO Box 19687. \\ New Orleans, Louisiana 70179, USA \\ ${ }^{2}$ Loyola University, Department of Biological Sciences, 6363 St. Charles Avenue, New Orleans, Louisiana 70118, USA \\ ${ }^{3}$ Mote Marine Laboratory, 1600 Thompson Parkway, Sarasota, Florida 34236, USA
}

\begin{abstract}
The lipophilic pigment content and composition and in vivo optical density (OD) spectra for batch cultures of the Florida (USA) red-tide dinoflagellate Gymnodinium breve Davis were analyzed after exposure to irradiance treatments representative of an irradiance gradient that cells might experience in a coastal water column. Decreases in total chlorophyll (chl) content (attributable to decreases in chls a, $c_{1} / c_{2}$ and $c_{3}$ ) and total carotenoid content (attributable to decreases in total fucoxanthin and 19'-acylofucoxanthins, and gyroxanthin-diester) coincided with exposure to increased irradiance. The relative abundances of chl pigments remained constant whereas decreases in the relative abundances of total fucoxanthin and 19'-acylofucoxanthins, and $\beta$ - $\psi$-carotene and an increase in the relative abundance of diadinoxanthin coincided with exposure to increased irradiance. Because gyroxanthin-diester has been observed only in a limited number of toxic dinoflagellates (of which $G$. breve is the only warm-water taxon), was consistently quantifiable throughout various irradiance-induced physiological states, and had a distinctive elution position and absorption maxima in the chromatographic eluent, this carotenoid may serve as a 'biomarker' for $G$. breve within Florida coastal waters. An analysis of variance, performed on fourthderivative plots derived from normalized OD spectra, identified portions of the OD spectra which differed among irradiance treatments. Designated wavelengths coincided with wave crests in the fourth-derivative plots representative of absorption maxima for total chl c $(460$ to 468,585 to $590 \mathrm{~nm})$ and total fucoxanthin and 19'-acylofucoxanthins, and diadinoxanthin (490 to $496 \mathrm{~nm}$ ). Stepwise discriminant analysis identified a set of 6 wavelengths $(403,541,546,509,673$ and $663 \mathrm{~nm})$ which optimally classified OD spectra for populations among irradiance treatments. This lack of correspondence between wavelengths identified by the 2 statistical techniques was not unexpected fourth-derivative analysis identified portions of the OD spectra where differences in the sharpness of curvature (as produced by absorption maxima of component pigments) occurred among treatments whereas discriminant analysis identified portions of the spectra which could be used to classify populations among treatments and did not necessarily have to correspond to absorption maxima. Such detectable differences in the bio-optical 'signatures' of $G$. breve indicate that previous light history, as manifested in the pigment component, could be incorporated into future pigment-based monitoring applications to allow for the detection and/or physiological characterization of problematic taxa prior to bloom status.
\end{abstract}

KEY WORDS: Chlorophyll - Carotenoid - Stepwise discriminant analysis · Fourth derivative - Highperformance liquid chromatography In vivoabsorption . Red tide Phytoplankton

\section{INTRODUCTION}

The recent increased incidence of harmful algal blooms has been attributed to 'hidden' taxa (Anderson et al. 1993, Hallegraeff 1993) whose growth and toxic- ity are triggered by a consortium of physical, chemical, and biological factors. Once established, harmful algal blooms typically are mono-specific or near mono-specific, reaching extremely high biomass over small spatial scales. Consequently, the bio-optical 'signatures' of 
the blooms are distinct and usually constant for an extended time period, thereby lending themselves to photosynthetic pigment-based applications, such as high-performance liquid chromatograph (HPLC)derived pigment analyses, in vivo absorption assays, and multi-spectral remote sensing.

Pigment-based applications provide for characterization of bloom dynamics in relevant temporal and spatial scales and in response to event-scale processes and/or perturbation affecting such dynamics (e.g Campbell et al. 1986, Tyler \& Stumpf 1989, Millie et al. 1993, Carrick \& Worth 1994) and may allow for identification of problematic flora prior to bloom status. However, pigment analyses, in vivo absorption assays, and remote sensing collect mutually exclusive, yet complementary, data sets. For example, the future deployment of multi-spectral satellite/airborne sensors and in situ transmissometers will evoke improved pigment scanning capabilities, thereby facilitating acquisition of remotely sensed imagery based on pigments other than chlorophyll (chl) a (see Millie et al. 1992, 1995, Richardson et al. 1994). The coupling of this information with accurate taxon-specific spectral absorption/reflectance and HPLC-confirmed pigment 'signatures' will be required to provide a previously unrecognized calibration of spectral reflectance data (Millie et al. 1993).

Blooms of the toxic dinoflagellate Gymnodinium breve Davis usually develop offshore of western Florida (USA) in the Gulf of Mexico (Steidinger 1975) and may be transported along the western coast of Florida, through the Florida Straits and along the eastern seaboard of the United States via the Loop Current, the Florida Current, and the Gulf Stream, respectively (Murphy et al. 1975, Tester et al. 1989, 1991). Physical forcing events (e.g. water circulation, tides, winds) can transport offshore assemblages to coastal waters (Steidinger \& Ingle 1972) where the release of brevetoxins from cells may cause deleterious effects on public health and finfish/shellfish and aquacultural fisheries (Steidinger et al. 1973, Steidinger \& Baden 1984, Riley et al. 1989).

Phototactic-induced vertical migration of Gymnodinium breve provides for maximum concentrations of

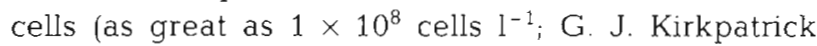
unpubl. data) within surface waters, often discoloring the water in red, brown and/or yellow hues (i.e. 'red tides'). Presumably, differences in bloom color are due to alterations in cell pigment content/composition in response to changing irradiance and/or cell senescence, which affect cell-specific absorption and spectral reflectance. Because knowledge of the alteration in the bio-optical signature of $G$. breve is necessary for accurate pigment-based monitoring applications, the intent of this study was to characterize the lipophilic pigment complex and the in vivo optical density (OD) spectra of $G$. breve in response to varying irradiance.

\section{METHODS}

Culture conditions and experimental design. Batch cultures of Gymnodinium breve (clone W53DB, Mote Marine Laboratory) were maintained in $\mathrm{f} / 20$ growth medium (Guillard \& Ryther 1962) within culture flasks at $25 \pm 1{ }^{\circ} \mathrm{C}$. A mixture of cool-white, and Vita-Lite fluorescent lamps provided the culture flasks with $60 \mu \mathrm{E}$ $\mathrm{m}^{-2} \mathrm{~s}^{-1}$ of photosynthetic active radiation (PAR) in a $12 \mathrm{~h}$ light: $12 \mathrm{~h}$ dark cycle (lights on at 06:00 h). All PAR measurements were made with a Biospherical Instruments, Inc., model QSL-100 quantum scalar irradiance sensor placed in culture flasks filled with growth medium. A sheet of $0.13 \mathrm{~mm}$ clear acetate was placed between the lamps and the flasks to minimize culture exposure to UV-B radiation produced by the lamps. To reduce changes in light transmission characteristics of the plastic during experimental treatment periods (see below), the acetate sheet was placed in position $100 \mathrm{~h}$ prior to the beginning of the irradiance treatment.

Nine 2.8 I Pyrex Fernbach flasks, each containing $1 \mathrm{l}$ of growth medium, were inoculated with an equal volume of an exponentially growing maintenance culture. The cultures were exposed to maintenance light conditions and incubated for 9 to $14 \mathrm{~d}$ until cell densities reached approximately 2.17 to $2.39 \times 10^{7}$ cells $\mathrm{I}^{-1}$ (see Table 1). The length of this incubation was chosen to ensure adequate biomass for bio-optical analyses and to ensure relatively equivalent physiological states among the cultures.

The 9 flasks were randomly divided into 3 groups; each group then was randomly assigned to 1 of 3 irradiance treatments (60 and $165 \mu \mathrm{E} \mathrm{m} \mathrm{m}^{-2} \mathrm{~s}^{-1} \mathrm{PAR}$ and $220 \mu \mathrm{E} \mathrm{m}^{-2} \mathrm{~s}^{-1}$ PAR + UV irradiance). These treatments were chosen to represent an irradiance gradient that cells might experience at distinct depths within a coastal water column (previous culture experience indicated that laboratory cultures of Gymnodinium breve would not sustain growth at irradiances greater than the greatest irradiance tested). A Phillips Corp. model F40UVB sun lamp, which had been preconditioned with a $72 \mathrm{~h}$ burn-in period, provided the UV irradiance. The UV lamp was controlled by a separate timer from that controlling the fluorescent lamps and was on from 10:00 to 14:00 h daily. The relative UVexposure level was determined using a Hamamatsu Corp. model G3614 UV-sensitive photodiode detector placed within an empty culture flask. Using this configuration, the experimental UV-exposure level was approximately $5 \%$ of the solar, sea-surface UV irradi- 
ance measured at noon in late spring. This method of comparison, using a broad-band UV detector $1>10 \%$ peak response between 260 to $400 \mathrm{~nm}$ ) and a lamp with peak emission at approximately $310 \mathrm{~nm}$, overemphasizes the UV-B component relative to the natural spectrum. UV-B radiation from the fluorescent lamps was attenuated by an acetate sheet for all flasks except those assigned to the $220 \mu \mathrm{E} \mathrm{m}^{-2} \mathrm{~s}^{-1}$ PAR + UV irradiance treatment.

On the initial day of the irradiance treatments (Day 0), aliquots from the 3 flasks for each treatment were pooled. This pooled volume was subsampled for culture cell density and bio-optical characterization (see below). The cultures then were exposed to their respective irradiance treatment. On Days 4 and 8 after exposure to irradiance treatments, cultures were analyzed for biomass and bio-optical characteristics (see below). Five replicate experiments were performed sequentially.

Biomass and bio-optical analyses. All sampling was performed between 13:00 and 14:00 h local time. For determination of culture biomass, cells of culture aliquots were preserved immediately with Utermöhl's solution and later enumerated using a hemacytometer (Guillard 1973). For analyses of lipophilic pigments and in vivo OD spectra, culture aliquots were filtered under low vacuum ( $<75 \mathrm{~mm} \mathrm{Hg}$ ) onto GF/F glass-fiber filters. Filters for lipophilic pigments were immediately frozen in liquid nitrogen and stored at $-20^{\circ} \mathrm{C}$ until analysis. Filters for in vivo absorption were immediately analyzed after filtration.

For pigment analyses, frozen filters were placed in $3 \mathrm{ml}$ of $100 \%$ acetone, sonicated and extracted in darkness at $-20^{\circ} \mathrm{C}$ for at least $1 \mathrm{~h}$. Filtered extracts $(75$ to $125 \mu \mathrm{l})$ were injected directly into a Hewlett Packard model 1090 HPLC equipped with a ODS-Hypersil $C_{18}$ column $(200 \times 4.6 \mathrm{~mm}, 4 \mu \mathrm{m})$ and a diode array detector set at $440 \mathrm{~nm}$. The mobile phase followed the tertiary gradient system described by Wright et al. (1991). Solvent flow rate was $1 \mathrm{ml} \mathrm{min}^{-1}$. The column temperature was $40^{\circ} \mathrm{C}$. Pigment peaks were identified and quantified by comparison of retention times and absorption spectra to those of authentic crystalline standards, including chl a (Sigma Chemical Company), fucoxanthin (Hoffman-LaRoche \& Company), and $\beta$-carotene (Sigma Chemical Company). All other pigments were identified by comparison to pigments extracted from phytoplankton cultures (see Wright et al. 1991) and quantified using the appropriate extinction coefficients (from Mantoura \& Llewellyn 1983).

In vivo OD spectra of cells collected on glass-fiber filters were recorded using a Varian model DMS-80 UV-VIS spectrophotometer (after Yentsch 1962; for a review see Cleveland \& Weidemann 1993). To minimize the loss of scattered light, filter holders were fabricated to position the filters as close as possible to the detector windows. The OD was zeroed at $750 \mathrm{~nm}$ for each sample. Prior to each sample scan, a glass-fiber filter, wetted with filtered media, was scanned to establish a 'blank' baseline. This baseline was subsequently subtracted from all sample scans. Because an objective of the study was to compare the OD spectra among treatment cultures of Gymnodinium breve only, OD data were not corrected for pathlength amplification $(\beta)$.

Statistical analyses. The effects of irradiance and exposure time on pigment content and ratio and the relative abundances of chl and carotenoid fractions within the total chl and carotenoid pigments were compared by an analysis of variance (ANOVA). The significance between pairs of variable means was analyzed by a least significant difference (LSD) analysis. LSD analyses were considered applicable only if the ANOVA indicated significant differences between variable means among irradiance and days (Snedecor \& Cochran 1980). Because only cells that had been exposed to $60 \mu \mathrm{E} \mathrm{m}^{-2} \mathrm{~s}^{-1}$ PAR were used as inoculum for the experimental flasks, no comparison among irradiance treatments could be made for Day 0 . Therefore, the ANOVA only compared values for Days 4 and 8 . To increase the variance associated with binomial proportion (percentage) data, relative abundances of chls and carotenoids were square-root- then arcsin-transformed prior to statistical analysis (see Snedecor \& Cochran 1980).

In vivo $\mathrm{OD}$ spectra first were normalized to each respective spectral mean OD (after Roesler et al. 1989). The spectral fourth derivative (Butler \& Hopkins 1970) then was computed for each normalized spectrum to resolve the position of the absorption peaks (see Owens et al. 1987, Bidigare et al. 1989, Smith \& Alberte 1994). An ANOVA was performed for each wavelength (391 to $725 \mathrm{~nm}$ ) in the fourth-derivative plots for cultures $8 \mathrm{~d}$ after exposure to irradiance treatments in order to detect wavelengths where the differ. ent irradiance treatments produced detectable differences in the shape of the OD spectra.

Stepwise discriminant analysis (Tabachnick \& Fidell 1983) was used to identify wavelengths allowing optimal classification of OD spectra for cultures exposed to distinct irradiance treatments (cf. Johnsen et al. 1994b). Normalized OD spectra of cultures $8 \mathrm{~d}$ after exposure to irradiance treatments were discriminated for every spectral wavelength between 400 and $700 \mathrm{~nm}$. Classification error rates, calculated by crossvalidation and re-substitution techniques, were used to determine which set of wavelengths sufficiently differentiated culture populations among irradiance treatments. These classification rates were obtained from a separate discriminant analysis using the wavelengths selected by the stepwise analysis. 


\section{RESULTS}

Daily cell counts of cultures in 2 of the experimental replicates indicated that the cultures were in logarithmic growth at the beginning of the treatment period and had transitioned to early stationary phase by the end of the experiment. On Day 4, biomass was relatively similar among populations exposed to irradiance treatments (Table 1). However, on Day 8, the biomass of populations exposed to $60 \mu \mathrm{E} \mathrm{m} \mathrm{m}^{-2} \mathrm{~s}^{-1}$ PAR were Ca 1.4-fold greater than those of populations exposed to $220 \mu \mathrm{E} \mathrm{m}^{-2} \mathrm{~s}^{-1} \mathrm{PAR}+\mathrm{UV}$ irradiance (due to termination of growth after Day 4 in populations exposed to $220 \mu \mathrm{E} \mathrm{m} \mathrm{m}^{-2} \mathrm{~s}^{-1} \mathrm{PAR}+\mathrm{UV}$ irradiance). Additionally, the dramatic decreases in the amounts of chls and carotenoids per unit cell on Days 4 and 8 from those on Day 0 (see Tables $1 \& 2$ ) were most likely attributable to the rapid cell division occurring in the culture populations.

Quantifiable lipophilic pigments within Gymnodinium breve determined by HPLC included chls $a$, $C_{1} / C_{2}$, and $C_{3}$ and the carotenoids 19'-butanoyloxyfucoxanthin, fucoxanthin, 19'-hexanoyloxyfucoxanthin, diadinoxanthin, gyroxanthin-diester and $\beta-\psi$-carotene (Fig. 1). Because chls $c_{1}$ and $c_{2}$ co-elute when using the HPLC solvent system employed here (see Wright et al. 1991), the presence of either (or both) pigment(s) was reported as chl $c_{1} / c_{2}$. Additionally, because baseline separations of 19'-butanoyloxyfucoxanthin, fucoxanthin and 19'-hexanoyloxyfucoxanthin were not consistently achieved, these pigments are (hereafter) reported collectively as total fucoxanthin and 19'acylofucoxanthins

Decreases in total chl content ( $p \leq 0.0309)$, attributable to decreases in chl a $(p \leq 0.0358)$, chls $c_{1} / c_{2}$ (p $\leq$ $0.0069)$ and chl $c_{3}(p \leq 0.0097)$ contents, coincided with increasing irradiance (Table 1). On both Days 4 and 8 , the chls $a_{1} c_{1} / c_{2}$ and $c_{3}$ contents of populations exposed to $60 \mu \mathrm{E} \mathrm{m}^{-2} \mathrm{~s}^{-1}$ PAR were ca 1.7-, 1.9- and 1.7-fold greater, respectively, than those in populations exposed to $165 \mu \mathrm{E} \mathrm{m}^{-2} \mathrm{~s}^{-1} \mathrm{PAR}$ and $220 \mu \mathrm{E} \mathrm{m}^{-2} \mathrm{~s}^{-1} \mathrm{PAR}$ + UV irradiance.

Decreases in total carotenoid content ( $\mathrm{p} \leq 0.0187$ ) attributable to decreases in total fucoxanthin and 19'acylofucoxanthin ( $p \leq 0.0129$ ) and gyroxanthin-diester $(\mathrm{p} \leq 0.0180)$ contents, coincided with increasing irradiance (Table 2). On Day 4, the total fucoxanthin and 19'acylofucoxanthins and gyroxanthin-diester contents of populations exposed to $60 \mu \mathrm{E} \mathrm{m}^{-2} \mathrm{~s}^{-1} \mathrm{PAR}$ were ca 1.4 and 1.7 -fold greater than those of populations exposed to $165 \mu \mathrm{E} \mathrm{m}^{-2} \mathrm{~s}^{-1}$ PAR and/or $220 \mu \mathrm{E} \mathrm{m}^{-2} \mathrm{~s}^{-1}$ PAR + UV irradiance. By Day 8 , the gyroxanthin-diester contents of populations exposed to $60 \mu \mathrm{E} \mathrm{m}^{-2} \mathrm{~s}^{-1}$ PAR were ca 1.7 -fold greater than populations exposed to $165 \mu \mathrm{E}$ $\mathrm{m}^{-2} \mathrm{~s}^{-1} \mathrm{PAR}$ and $220 \mu \mathrm{E} \mathrm{m} \mathrm{m}^{-2} \mathrm{~s}^{-1} \mathrm{PAR}+\mathrm{UV}$ irradiance. Diadinoxanthin and $\beta-\psi$-carotene contents were not (statistically) altered with increasing irradiance.

The relative abundances of chls and carotenoids exhibited non-uniform responses to irradiance treatments. Chls $a, c_{1} / c_{2}$ and $c_{3}$ accounted for ca 90,6 , and $4 \%$, respectively, of the total chl within Gymnodinium breve (Table 3 ). The relative abundances of chls

Table 1. Biomass and chlorophyll (chl) content of Gymnodinium breve populations exposed to irradiances of 60 and $165 \mu \mathrm{E} \mathrm{m}^{-2}$ $\mathrm{s}^{-1}$ photosynthetic active radiation (PAR) and $220 \mu \mathrm{E} \mathrm{m}^{-2} \mathrm{~s}^{-1} \mathrm{PAR}+5 \%$ of surface ultraviolet (UV) irradiance. Data are means \pm standard errors $(n=5)$. Day (D) and irradiance (I) effects (as determined by analysis of variance) are significant ( $p \leq 0.05$ ) if designated. Variable means within and between Days 4 and 8 with different superscripted letters are significantly different ( $p \leq$ 0.05 ). Least significant difference analyses based on 17 degrees of freedom

\begin{tabular}{|c|c|c|c|c|c|}
\hline Variable & Effects & Irradiance & Day 0 & Day 4 & Day 8 \\
\hline Biomass (cells $\times 10^{\top} 1^{-1}$ ) & $\mathrm{D}$ & $\begin{array}{c}60 \\
165 \\
220+U V\end{array}$ & $\begin{array}{l}2.17 \pm 0.19 \\
2.18 \pm 0.10 \\
2.39 \pm 0.25\end{array}$ & $\begin{array}{l}2.48 \pm 0.04^{a} \\
2.73 \pm 0.03^{a} \\
2.80 \pm 0.05^{a, b}\end{array}$ & $\begin{array}{l}3.68 \pm 0.53^{b} \\
3.11 \pm 0.18^{a b} \\
2.57 \pm 0.33^{a}\end{array}$ \\
\hline Chl a (pg cell $\left.l^{-1}\right)$ & I & $\begin{array}{c}60 \\
165 \\
220+U V\end{array}$ & $\begin{array}{l}8.68 \pm 0.60 \\
7.02 \pm 1.01 \\
758 \pm 0.71\end{array}$ & $\begin{array}{l}5.00 \pm 0.89^{a} \\
3.31 \pm 0.09^{a b b} \\
2.75 \pm 1.69^{a b b}\end{array}$ & $\begin{array}{l}3.66 \pm 1.28^{a . b} \\
2.08 \pm 0.31^{b} \\
1.99 \pm 0.52^{b}\end{array}$ \\
\hline $\mathrm{Chl} c_{1}$ and $c_{2}\left(\right.$ pg cell $\left.{ }^{-1}\right)$ & D, I & $\begin{array}{c}60 \\
165 \\
220+U V\end{array}$ & $\begin{array}{l}0.59 \pm 0.03 \\
0.50 \pm 0.08 \\
0.52 \pm 0.06\end{array}$ & $\begin{array}{l}0.35 \pm 0.04^{a} \\
0.21 \pm 0.00^{b} \\
0.16 \pm 0.01^{b}\end{array}$ & $\begin{array}{l}0.23 \pm 0.03^{b} \\
0.13 \pm 0.08^{b} \\
0.11 \pm 0.06^{b}\end{array}$ \\
\hline $\mathrm{Chl} \mathrm{C}_{3}\left(\mathrm{pg} \mathrm{cell}^{-1}\right)$ & $D, I$ & $\begin{array}{c}60 \\
165 \\
220+\mathrm{UV}\end{array}$ & $\begin{array}{l}0.34 \pm 0.18 \\
0.25 \pm 0.01 \\
0.52 \pm 0.08\end{array}$ & $\begin{array}{l}0.23 \pm 0.01^{a} \\
0.15 \pm 0.02^{b} \\
0.12 \pm 0.01^{b, c}\end{array}$ & $\begin{array}{l}0.13 \pm 0.03^{b, c} \\
0.08 \pm 0.01^{c} \\
0.08 \pm 0.02^{c}\end{array}$ \\
\hline Total chl (pg cell ${ }^{-1}$ ) & I & $\begin{array}{c}60 \\
165 \\
220+\mathrm{UV}\end{array}$ & $\begin{array}{l}9.61 \pm 0.63 \\
7.77 \pm 1.10 \\
8.41 \pm 0.85\end{array}$ & $\begin{array}{l}5.58 \pm 0.93^{\circ} \\
3.68 \pm 0.10^{a t b} \\
3.02 \pm 0.19^{b}\end{array}$ & $\begin{array}{l}4.02 \pm 1.38^{a, b} \\
2.29 \pm 0.33^{b} \\
2.17 \pm 0.57^{b}\end{array}$ \\
\hline
\end{tabular}


Table 2. Carotenoid content and chlorophyll/carotenoid ratio of Gymnodinium breve populations exposed to irradiances of 60 and $165 \mu \mathrm{E} \mathrm{m} \mathrm{m}^{-2} \mathrm{~s}^{-1} \mathrm{PAR}$ and $220 \mu \mathrm{E} \mathrm{m} \mathrm{m}^{-2} \mathrm{~s}^{-1} \mathrm{PAR}+5 \%$ of surface UV irradiance. Data are means \pm standard errors $(\mathrm{n}=5)$. Day (D) and irradiance (I) effects (as determined by analysis of variance) are significant $(\mathrm{p} \leq 0.05$ ) if designated. Variable means within and between Days 4 and 8 with different superscripted letters are significantly different $(p \leq 0.05)$. Least significant difference analyses based on 17 degrees of freedom

\begin{tabular}{|c|c|c|c|c|c|}
\hline Pigment & Effect & lrradiance & Day 0 & Day 4 & Day 8 \\
\hline $\begin{array}{l}\text { Fucoxanthin }+ \\
19^{\prime} \text {-acylofucoxanthins (pg cell }{ }^{-1} \text { ) }\end{array}$ & D, I & $\begin{array}{c}60 \\
165 \\
220+U V\end{array}$ & $\begin{array}{l}6.34 \pm 0.13 \\
5.25 \pm 0.62 \\
5.53 \pm 0.13\end{array}$ & $\begin{array}{l}3.78 \pm 0.36^{b} \\
2.45 \pm 0.15^{b} \\
2.02 \pm 0.13^{b}\end{array}$ & $\begin{array}{l}2.37 \pm 0.63^{b} \\
1.50 \pm 0.24^{b} \\
1.40 \pm 0.30^{b}\end{array}$ \\
\hline Diadinoxanthin (pg cell-1) & $\mathrm{D}$ & $\begin{array}{c}60 \\
165 \\
220+U V\end{array}$ & $\begin{array}{l}0.99 \pm 0.02 \\
0.92 \pm 0.10 \\
0.97 \pm 0.12\end{array}$ & $\begin{array}{l}0.64 \pm 0.07^{\mathrm{a}} \\
0.62 \pm 0.00^{\mathrm{a}} \\
0.56 \pm 0.04^{\mathrm{a} b}\end{array}$ & $\begin{array}{l}0.39 \pm 0.08^{b . c} \\
0.37 \pm 0.04^{b . c} \\
0.33 \pm 0.07^{c}\end{array}$ \\
\hline Gyroxanthin-diester (pg cell-1 ${ }^{-1}$ ) & D. I & $\begin{array}{c}60 \\
165 \\
220+U V\end{array}$ & $\begin{array}{l}0.61 \pm 0.01 \\
0.51 \pm 0.06 \\
0.57 \pm 0.08\end{array}$ & $\begin{array}{l}0.32 \pm 0.01^{d} \\
0.26 \pm 0.02^{a, b} \\
0.22 \pm 0.01^{b \cdot c}\end{array}$ & $\begin{array}{l}0.26 \pm 0.043^{\mathrm{a} b \mathrm{~b}} \\
0.16 \pm 0.10^{c} \\
0.15 \pm 0.04^{c}\end{array}$ \\
\hline$\beta$ - $\psi$-carotene (pg cell ${ }^{-1}$ ) & & $\begin{array}{c}60 \\
165 \\
220+U V\end{array}$ & $\begin{array}{l}0.12 \pm 0.02 \\
0.11 \pm 0.01 \\
0.09 \pm 0.01\end{array}$ & $\begin{array}{l}0.06 \pm 0.04 \\
0.04 \pm 0.01^{d i} \\
0.01 \pm 0.00^{d}\end{array}$ & $\begin{array}{l}0.04 \pm 0.03^{\mathrm{a}} \\
0.01 \pm 0.01^{\mathrm{a}} \\
0.01 \pm 0.00^{\mathrm{a}}\end{array}$ \\
\hline Total carotenoids (pg cell ${ }^{-1}$ ) & $\mathrm{D}, \mathrm{I}$ & $\begin{array}{c}60 \\
165 \\
220+U V\end{array}$ & $\begin{array}{l}6.79 \pm 0.18 \\
8.06 \pm 0.80 \\
7.17 \pm 0.83\end{array}$ & $\begin{array}{l}4.79 \pm 0.46^{\circ} \\
3.37 \pm 0.16^{b} \\
2.81 \pm 0.29^{b . c}\end{array}$ & $\begin{array}{l}3.07 \pm 0.67^{b, c} \\
2.04 \pm 0.18^{b, c} \\
1.90 \pm 0.41^{r}\end{array}$ \\
\hline Total chlorophyll/total carotenoid & & $\begin{array}{c}60 \\
165 \\
220+U V\end{array}$ & $\begin{array}{l}1.19 \pm 0.05 \\
1.14 \pm 0.03 \\
1.17 \pm 0.02\end{array}$ & $\begin{array}{l}1.16 \pm 0.08^{\mathrm{a}} \\
1.09 \pm 0.02^{\mathrm{a}} \\
1.08 \pm 0.04^{\mathrm{d}}\end{array}$ & $\begin{array}{l}1.27 \pm 0.17 \mathrm{a} \\
1.12 \pm 0.06^{a} \\
1.13 \pm 0.05^{a}\end{array}$ \\
\hline
\end{tabular}

remained constant among irradiance treatments within a particular sampling day. Total fucoxanthin and 19'-acylofucoxanthins, diadinoxanthin, gyroxanthin-diester and $\beta$ - $\psi$-carotene accounted for ca 76,15 , 8 , and $1 \%$, respectively, of the total carotenoids (Table 3). Decreases in the relative abundances of total
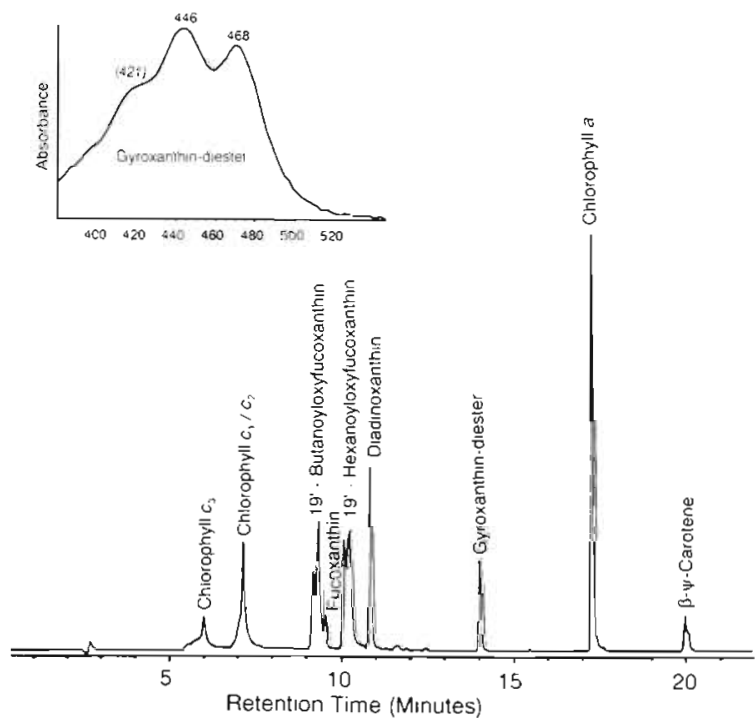

Fig. 1. Representative, reverse-phase HPLC chromatogram of lipophilic pigments extracted from Gymnodinium breve. The spectral plot for gyroxanthin-diester (insert) identifies the distinct absorption maxima for this carotenoid fucoxanthin and 19'-acylofucoxanthins ( $p \leq 0.0001)$ and $\beta$ - $\psi$-carotene $(p \leq 0.0016)$ and an increase in the relative abundance of diadinoxanthin ( $p \leq 0.0001$ ) coincided with increasing irradiance. On Days 4 and 8 in populations exposed to $165 \mu \mathrm{E} \mathrm{m} \mathrm{m}^{-2} \mathrm{~s}^{-1} \mathrm{PAR}$ and $220 \mu \mathrm{E} \mathrm{m}^{-2} \mathrm{~s}^{-1} \mathrm{PAR}+\mathrm{UV}$ irradiance, relative abundances of total fucoxanthin and 19'-acylofucoxanthins, and diadinoxanthin decreased and increased, respectively, ca $7 \%$ from that of populations exposed to $60 \mu \mathrm{E}$ $\mathrm{m}^{-2} \mathrm{~s}^{-1}$ PAR. On Day 8 , the relative abundance of $\beta-\psi$ carotene was ca 3 -fold greater in populations exposed to $60 \mu \mathrm{E} \mathrm{m} \mathrm{m}^{-2} \mathrm{~s}^{-1} \mathrm{PAR}$ than that of populations exposed to $220 \mu \mathrm{E} \mathrm{m} \mathrm{m}^{-2} \mathrm{~s}^{-1} \mathrm{PAR}+\mathrm{UV}$ irradiance.

Fourth-derivative plots of the OD spectra for Gymnodinium breve (Fig. 2) produced wave crests indicating points within OD spectra where shoulders or peaks occurred. Conversely, wave troughs indicated points within the spectra where valleys (between shoulders and peaks) occurred. The occurrence of wave crests was representative of absorption maxima of the component pigments whereas wave troughs delineated regions of weaker absorption between the peak maxima. Wave crests in the fourth-derivative plots (and the pigments to which they corresponded; after Bidigare et al. 1990, Johnsen et al. 1994a, b, Smith \& Alberte 1994) occurred at $412 \mathrm{~nm}$ (chl a), $438 \mathrm{~nm}$ (chl a, diadinoxanthin), $466 \mathrm{~nm}$ (total chl $C_{\text {, }}$ diadinoxanthin), $495 \mathrm{~nm}$ (total fucoxanthin and 19'acylofucoxanthin, diadinoxanthin), $589 \mathrm{~nm}$ (total 
Table 3. Percent relative abundance of chlorophyll and carotenoid fractions in total chlorophyll and carotenoid pigments, respectively, of Gymnodinium breve populations exposed to irradiances of 60 and $165 \mu \mathrm{E} \mathrm{m} \mathrm{m}^{-2} \mathrm{~s}^{-1}$ PAR and $220 \mu \mathrm{E} \mathrm{m}^{-2} \mathrm{~s}^{-1} \mathrm{PAR}+5 \%$ of surface UV irradiance. Data are means \pm standard errors $(n=5)$. Day (D) and irradiance (I) effects (as determined by analysis of variance) are significant $(\mathrm{p} \leq 0.05)$. Variable means within and between Days 4 and 8 with different superscripted letters are significantly different $(p \leq 0.05)$ if designated. Least significant difference analyses based on 17 degrees of freedom

\begin{tabular}{|c|c|c|c|c|c|}
\hline Pigment & Effect & Irradiance & Day 0 & Day 4 & Day 8 \\
\hline \multicolumn{6}{|l|}{ Chlorophylls } \\
\hline \multirow[t]{3}{*}{ a } & $D$ & 60 & $89.89 \pm 0.40$ & $89.55 \pm 0.65^{\text {a }}$ & $90.31 \pm 0.66^{2}$ \\
\hline & & 165 & $89.96 \pm 0.34$ & $89.63 \pm 0.51$ & $90.61 \pm 0.34^{\mathrm{a}}$ \\
\hline & & $220+U V$ & $89.97 \pm 0.51$ & $89.96 \pm 0.96^{a}$ & $90.93 \pm 0.52^{a}$ \\
\hline \multirow[t]{3}{*}{$c_{1}$ and $c_{2}$} & $D_{1} \mathrm{I}$ & 60 & $6.52 \pm 0.27$ & $6.42 \pm 0.41^{a}$ & $5.98 \pm 0.17^{a, b}$ \\
\hline & & 165 & $6.71 \pm 0.34$ & $6.11 \pm 0.19^{a}$ & $5.68 \pm 0.32^{a . b}$ \\
\hline & & $220+U V$ & $6.44 \pm 0.31$ & $5.64 \pm 0.43^{a, b}$ & $5.11 \pm 0.16^{b}$ \\
\hline \multirow[t]{3}{*}{$c_{3}$} & & 60 & $3.58 \pm 0.09$ & $4.03 \pm 0.48^{\mathrm{a}}$ & $3.71 \pm 0.34^{a}$ \\
\hline & & 165 & $3.33 \pm 0.15$ & $4.27 \pm 0.19^{a}$ & $3.71 \pm 0.18^{a}$ \\
\hline & & $220+U V$ & $3.59 \pm 0.34$ & $4.40 \pm 0.54^{a}$ & $3.95 \pm 0.37^{\mathrm{a}}$ \\
\hline \multicolumn{6}{|l|}{ Carotenoids } \\
\hline Fucoxanthin and & I & 60 & $79.64 \pm 0.96$ & $78.67 \pm 0.15^{a}$ & $77.89 \pm 0.67^{\mathrm{a}}$ \\
\hline \multirow[t]{2}{*}{$19^{\prime}$-acylofucoxanthins } & & 165 & $78.54 \pm 1.21$ & $73.59 \pm 1.16^{\mathrm{b}}$ & $74.64 \pm 1.18^{b}$ \\
\hline & & $220+U V$ & $78.62 \pm 1.41$ & $72.17 \pm 0.81^{b}$ & $72.92 \pm 0.95^{b}$ \\
\hline \multirow[t]{3}{*}{ Diadinoxanthin } & 1 & 60 & $11.76 \pm 0.52$ & $13.25 \pm 0.15^{\mathrm{a}}$ & $12.67 \pm 0.17^{\mathrm{d}}$ \\
\hline & & 165 & $12.81 \pm 0.81$ & $18.13 \pm 0.65^{b, c}$ & $17.00 \pm 0.96^{b}$ \\
\hline & & $220+U V$ & $12.68 \pm 0.86$ & $19.78 \pm 0.39^{b, c}$ & $18.69 \pm 1.09^{b, c}$ \\
\hline \multirow[t]{3}{*}{ Gyroxanthin-diester } & $\mathrm{D}$ & 60 & $7.32 \pm 0.29$ & $6.79 \pm 0.47^{a}$ & $8.11 \pm 0.65^{\circ}$ \\
\hline & & 165 & $7.22=0.30$ & $7.16 \pm 0.45^{\circ}$ & $7.81 \pm 0.23^{\mathrm{a}}$ \\
\hline & & $220+U V$ & $7.51 \pm 0.43$ & $7.48 \pm 0.53^{a}$ & $7.92 \pm 0.20^{d}$ \\
\hline \multirow[t]{3}{*}{$\beta$ - $\psi$-carotene } & I & 60 & $1.27 \pm 0.18$ & $1.27 \pm 0.45^{a, b}$ & $1.32 \pm 0.39^{\mathrm{a}}$ \\
\hline & & 165 & $1.43 \pm 0.11$ & $1.12 \pm 0.19^{\star a, b}$ & $0.55 \pm 0.13^{a, b}$ \\
\hline & & $220+U V$ & $1.19 \pm 0.19$ & $0.56 \pm 0.16^{a, b}$ & $0.46 \pm 0.02^{b}$ \\
\hline
\end{tabular}

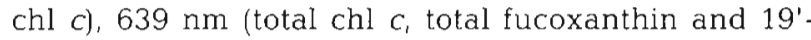
acylofucoxanthin), and $677 \mathrm{~nm}$ ( $\mathrm{chl}$ a).

The ANOVA identified wavelengths of the fourthderivative plots derived from $O D$ spectra which differed among the irradiance treatments $(p \leq 0.05)$. Because it was our intent only to identify portions of the OD spectra which differed, the significance between pairs of wavelength means was not determined. Wavelengths having a significant $F$-value (Fig. 3) directly coincided with the apex of wave crests in the fourth-derivative plots representative of absorption maxima for total chl $c$ ( 460 to 468,585 to $590 \mathrm{~nm}$ ) and total fucoxanthin and 19'-acylofucoxanthins and diadinoxanthin (490 to $496 \mathrm{~nm}$ ) (see Fig. 2). The ANOVA also identified significant $F$-values for 409 and $682 \mathrm{~nm}$, wavelengths which coincided with the shoulders of wave crests in the fourth-derivative plots representative of absorption maxima for chl a.

The stepwise discriminant analysis identified 13 wavelengths as optimal classifiers of OD spectra for populations exposed to distinct irradiance treatments. The set of 6 wavelengths $(403,541,546,509,673$ and $663 \mathrm{~nm}$; in the cumulative order of wavelength selection) fully optimized $(100 \%)$ the classification of cultures (Table 4, Fig. 4). Obviously, the remaining wavelengths chosen by the analysis $(400,483,407,405,589$,
507 and $586 \mathrm{~nm}$; in the cumulative order of wavelength selection of 7 through 13) could not improve on this optimization and, therefore, were not considered.

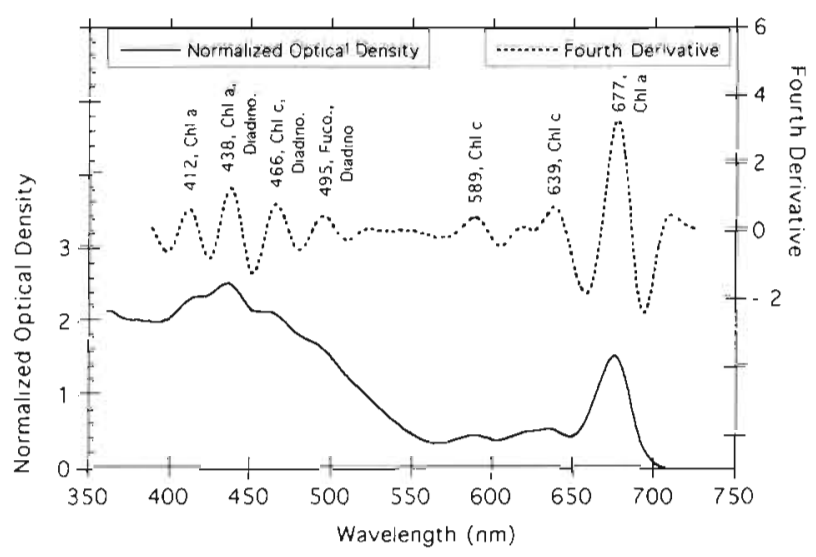

Fig. 2. A representative, normalized optical density (OD) spectrum and associated fourth-derivative plot for Gymnodinium breve. The wave crests of the fourth-derivative plot correspond to peaks and shoulders of the OD spectrum representative of absorption maxima for component pigments. The approximate wavelength of and the primary chlorophyll (Chl) and carotenoid (Fuco: total fucoxanthin and 19'-acylofucoxanthins; Diadino: diadinoxanthin) pigment(s) responsible for the absorption maxima are indicated 


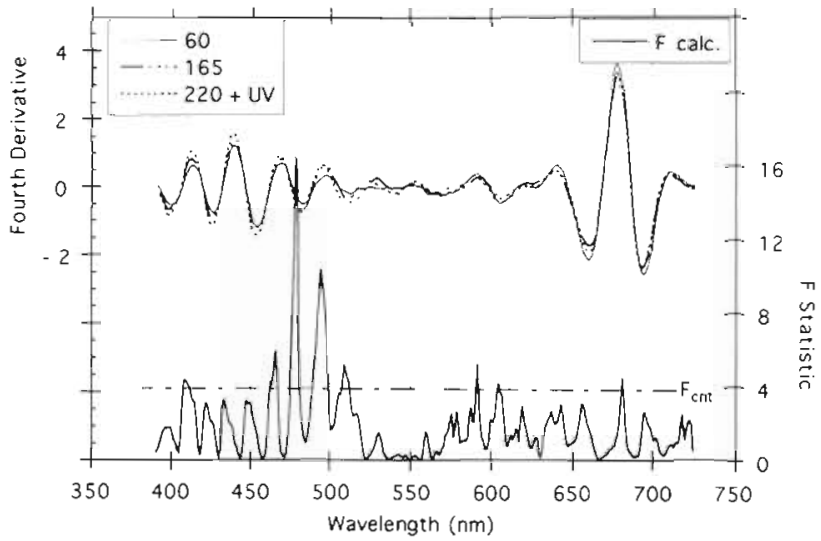

Fig. 3. Mean fourth-derivative plots of OD spectra $(n=5)$ for Gymnodinium breve populations $8 \mathrm{~d}$ after exposure to irradiances of 60 and $165 \mu \mathrm{E} \mathrm{m} \mathrm{m}^{-2} \mathrm{~s}^{-1} \mathrm{PAR}$ and $220 \mu \mathrm{E} \mathrm{m} \mathrm{m}^{-2} \mathrm{~s}^{-1} \mathrm{PAR}$ $+5 \%$ of surface UV irradiance. The wavelength-dependent $F$-statistic $\left(F_{\text {calc }}\right)$ and the significant $F$-value $\left(F_{\text {crnt }}\right)$ from the analysis of variance of the fourth derivatives are overlain to depict the regions of the OD spectra to be distinct among irradiance treatments

\section{DISCUSSION}

The carotenoid peridinin is the primary light-harvesting pigment and also is considered the diagnostic pigment for most autotrophic dinoflagellates (Jeffrey et al. 1975, Millie et al. 1993) Gymnodinium breve does not have peridinin, but rather has fucoxanthin and 19 '-acylofucoxanthins as the primary light-harvesting pigments, a condition observed in several prymnesiophytes and chrysophytes and a few dinoflagellates (e.g. Jeffrey et al. 1975, Tangen \& Bjørnland 1981, Haxo 1985, Bjørnland et al. 1988, Hooks et al. 1988 , Johnsen et al. 1992, Johnsen \& Sakshaug 1993). The accessory chls observed in $G$. breve included chls $C_{1} / C_{2}$ and $c_{3}$. However, because the HPLC method used here cannot differentiate between chls $c_{1}$ and $c_{2}$, we were unable to definitively indicate whether one or both pigments occur. Jeffrey (1976) reported that chl $c_{1}$ is

Table 4. Wavelengths derived from stepwise discriminant analysis allowing optimal classification of optical density spectra for Gymnodinium breve populations among irradiance treatments

\begin{tabular}{|ccc|}
\hline $\begin{array}{c}\text { Cumulative no. } \\
\text { of wavelengths }\end{array}$ & $\begin{array}{c}\text { Wavelength } \\
\text { (nm) }\end{array}$ & $\begin{array}{c}\text { Percent successful } \\
\text { classifications (\%) }\end{array}$ \\
\hline 1 & 403 & 40 \\
2 & 541 & 60 \\
3 & 546 & 73 \\
4 & 509 & 93 \\
5 & 673 & 93 \\
6 & 663 & 100 \\
\hline
\end{tabular}

present in almost all chromophytes (except the peridinin-based dinoflagellates) and that $c h l c_{2}$ is present in several fucoxanthin-based dinoflagellates. Bidigare

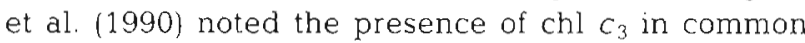
bloom-forming chromophytes, including $G$. breve. These lines of evidence support the hypothesis that the fucoxanthin-based dinoflagellates arose from endosymbiosis of colorless flagellates with chromophytes, such as chrysophytes and/or prymnesiophytes (Jeffrey 1976, Bjørnland et al. 1988).

Vertical migration of phototactic cells within the water column provides for variable exposure to photon flux density and spectral quality. Presumably, differences in the color of 'red tide' assemblages are due to distinct pigment alterations in response to photoacclimation and/or pigment degradation due to cell senescence. Although culture populations of Gymnodinium breve had transitioned to early stationary phase by the end of the experiment, cell senescence was not observed as (1) cells continued diurnal vertical migrations throughout the entire experiment under all treatment irradiances, (2) cell sediment deposits (such as those observed in maintenance culture carboys when the populations 'crash') were not observed in any experimental flasks, and (3) chlorophyll-degradation products (such as pheophytin) commonly associated with cell senescence were not observed in any pigment chromatogram. Consequently, differences in photosynthetic pigments and/or in vivo OD spectra among treatment cultures were attributed to differences in irradiance.

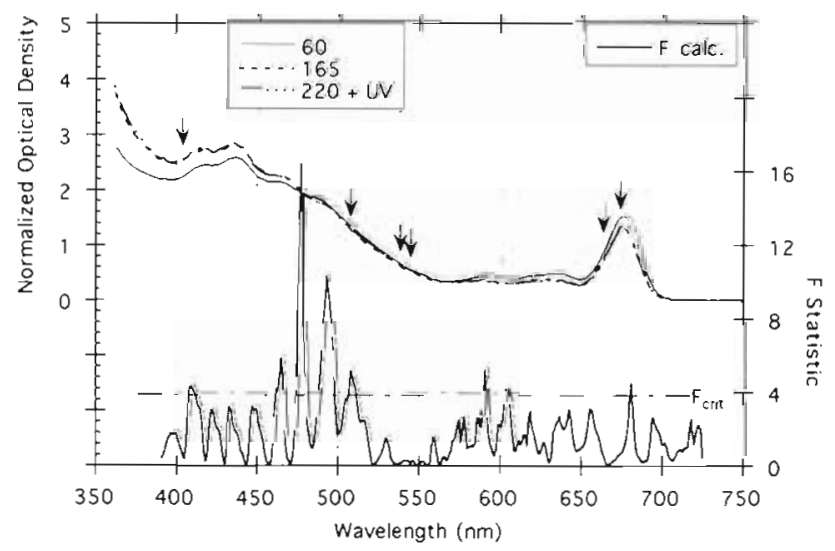

Fig. 4. Mean, normalized OD spectra $(n=5)$ for Gymnodinium breve cultures $8 \mathrm{~d}$ after exposure to irradiances of 60 and $165 \mu \mathrm{E} \mathrm{m}^{-2} \mathrm{~s}^{-1}$ PAR and $220 \mu \mathrm{E} \mathrm{m}^{-2} \mathrm{~s}^{-1}$ PAR $+5 \%$ of surface UV irradiance. The wavelength-dependent $F$-statistic $\left(F_{\text {calc }}\right)$ and the significant $F$-value ( $\left.F_{\text {crit }}\right)$ from the analysis of variance of the fourth derivatives are overlain to depict the regions of the $O D$ spectra to be distinct among irradiance treatments. The wavelengths of OD spectra identified by the stepwise discriminant analysis to be distinct among irradiance treatments are indicated by arrows 
Lipophilic pigments within Gymnodinium breve exhibited non-uniform responses to irradiance treatments, most likely resulting from alterations in the size of the light-harvesting components associated within each photosynthetic unit rather than alterations in the cellular concentrations of the photosynthetic unit (after Prézelin 1976, Schofield et al. 1990). Culture populations exposed to $60 \mu \mathrm{E} \mathrm{m} \mathrm{m}^{-2} \mathrm{~s}^{-1}$ PAR had greater chls a and $c_{1}$ total fucoxanthin and $19^{\prime}$-acylofucoxanthins, and gyroxanthin-diester contents than populations exposed to greater irradiance. Because chls $a_{1} c_{2}$ and $c_{3}$, fucoxanthin, and the 19'-acylofucoxanthins are photosynthetically active (Haxo 1985, Schofield et al. 1990, Johnsen et al. 1994a), alterations in these pigments would be expected. Diadinoxanthin, the second major carotenoid component in G. breve, is considered a photo-protectant pigment (Demers et al. 1991, Brunet et al. 1993) and the content of this pigment would be expected to increase with increasing irradiance. Although the cell contents of diadinoxanthin and $\beta-\psi$-carotene were not (statistically) altered, the relative abundance of these pigments to the total carotenoid pool increased and decreased, respectively, upon exposure to increased irradiance.

The exact environmental conditions leading to harmful algal blooms are poorly understood (see Paerl 1988). Consequently, it is extremely difficult to effectively predict the occurrence and magnitude of a bloom, thereby ensuring an 'after-the-fact' management strategy dependent upon accurate water-quality evaluation (H. Paerl, Institute of Marine Sciences, University of North Carolina, Morehead City, NC 28557 , USA, pers. comm.). Current monitoring efforts rely on microscopic identification and enumeration of harmful taxa in water samples. However, such a microscopicbased monitoring system requires a high level of taxonomic skill, usually takes considerable time, and can be highly variable among personnel (Millie et al. 1993). As such, the implementation of an alternative and/or complimentary evaluation system for predicting bloom occurrence and dynamics is highly desirable. Diagnostic pigment signatures and in vivo OD spectra can effectively differentiate among most phylogenetic groups of micro- and macroalgae and, sometimes, taxa within a variety of habitats (Millie et al. 1993, Johnsen et al. 1994b, Smith \& Alberte 1994\}. If such diagnostic pigments and/or spectra would allow for detecting the presence of harmful taxa prior to bloom status, a rapid, objective, and economical 'biomarker' protocol easily could be deployed for monitoring applications over temporal and spatial scales relevant to fisheries and water-quality management.

To be adequate biomarkers, pigment signatures and OD spectra must be unique to an organism or small group of closely related organisms, be relatively stable throughout various physiological states of the organism, and have distinct chromatographic and/or absorption characteristics to allow for definitive recognition. The major carotenoids and accessory chl pigments within Gymnodinium breve also are found in other chromophytes (see above) and have absorption maxima within HPLC eluent in a 4 to $10 \mathrm{~nm}$ range, characteristics which eliminate these pigments as possible biomarkers. However, gyroxanthin-diester may be a diagnostic pigment for $G$. breve within Florida coastal waters. This pigment only has been reported from the toxic dinoflagellates Gyrodinium aureolum Hulbert, Gymnodinium galatheanum Braarud and G. breve, all of which have fucoxanthin and/or 19'-acylofucoxanthins as the major light-harvesting carotenoid(s) (Johnsen \& Sakshaug 1993). Of these taxa, only $G$. breve can be considered a warm-water taxon (see Andersen et al. 1991) and would be expected to occur in Florida coastal waters. Additionally, gyroxanthindiester was a minor, yet stable, component of the total carotenoids in $G$. breve, being consistently detectable and quantifiable in populations exposed to all irradiance treatments. Finally, the distinct elution position and absorption maxima in the HPLC eluent (see Fig. 1) for gyroxanthin-diester allow for it to be distinguished easily from other carotenoids in chromatographic separations.

Fourth-derivative analysis identified portions of the OD spectra which had the greatest curvature as produced by absorption of light-harvesting pigments. A large wave crest in the fourth-derivative plot did not necessarily correspond to a large amount of pigment. Rather, differences in the height of the wave crests indicated differences in the shape (sharpness of curvature) of the OD spectra, thereby indicating qualitative alterations of the light-harvesting pigments. Consequently, this sensitivity to differences in shape makes the fourth-derivative analysis a useful tool for rapid assessment of pigment alterations within blooms. For example, wavelengths having a significant $F$-value directly corresponded with absorption maxima for chl $c$ and total fucoxanthin and 19'-acylofucoxanthins, pigments whose cell contents were significantly altered by increasing irradiance. The ANOVA also identified significant $F$-values for 409 and $682 \mathrm{~nm}$, suggesting that alterations in chl a may have been responsible for differences among fourth-derivative plots. However, these wavelengths did not directly correspond to the absorption maxima of chl a (i.e. apex of wave crests in the fourth-derivative plots) and no differences among fourth-derivative plots at $438 \mathrm{~nm}$, the wavelength representative of the strongest absorption maxima for chl a, were observed.

On the other hand, stepwise discriminant analysis selected a set of wavelengths which could be used for 
differentiating among spectra. Stepwise discriminant analysis selects wavelengths individually and does not take into account potential relationships among wavelengths (e.g. distinct portions of the OD spectrum having distinct pigment absorption, yet similar light-harvesting functions). Wavelengths identified by stepwise discriminant analysis may not necessarily correspond to absorption peaks of the component light-harvesting pigments, but more likely, should fall between the peaks where differences among OD spectra are maximum. Indeed, in comparisons of the irradiance treatments for Gymnodinium breve, wavelengths identified by the ANOVA for the fourth-derivative plots did not correspond to wavelengths identified by stepwise discriminant analysis for the in vivo OD spectra (see Fig. 4).

Utilizing stepwise discriminant analysis for differentiating among normalized in vivo OD spectra, Johnsen et al. (1994b) successfully grouped phylogenetically related species of phytoplankton. Their ability to differentiate among taxa decreased slightly when spectra from populations of the same taxa acclimated to distinct irradiances were included in the analysis. Obviously, their inclusion of intra-specific variability attributable to physiological state with the variability attributable to inter-specific differences effectively increased the variance of the discriminant. The wavelengths of the OD spectra denoted by Johnsen et al (1994b) to be taxonomically dependent $(481,535,586,628$ and $649 \mathrm{~nm})$ were different from the wavelengths identified by stepwise discriminant analysis for Gymnodinium breve to be irradiance dependent. This difference, most likely, occurred because the former wavelengths were intended for differentiating among 31 taxa belonging to 11 distinct phylogenetic groups whereas the latter wavelengths only were intended to differentiate among irradianceinduced physiological states for a single taxon. Using fourth-derivative analysis on in vivo OD spectra, Smith \& Alberte (1994) also were able to detect differences among macrophytes acclimated to distinct irradiances. These results indicate that phylogenetically distinct algal taxa can be differentiated based on bio-optical characteristics.

In this study, cultures of Gymnodinium breve exposed to distinct irradiances exhibited quantitative differences in lipophilic pigment 'signatures' and in the shape of the in vivo OD spectrum. This suggests that for mono-specific blooms, previous light history, as manifested in the pigment component, is detectable through pigment-based applications such as HPLCbased pigment and in vivo OD analyses. In the future, the coupling of data acquired through in situ multiwavelength transmissometers and/or hyperspectral satellite/airborne-based sensors with such bio-optical characterizations may permit the determination of early bloom history, thereby leading to a greater understanding of the mechanisms triggering and forcing harmful algal blooms.

Acknowledgements. Mention of proprietary names are necessary to report factually on available data; however, the U.S. Department of Agriculture, Loyola University, and Mote Marine Laboratory neither guarantee nor warrant the standard of a product and imply no approval of a product to the exclusion of others that may be suitable. This research was supported, in part, by grants from the Florida Department of Natural Resources to Mote Marine Laboratory. We express appreciation to Robert Lindsley for assisting in culturing and sampling preparations and to Geir Johnsen for confirming the identification of the carotenoid gyroxanthin-diester. We thank John Cullen, Gary Fahnenstiel, Casey Grimm, David Klarer, Raphael Jovine, James Pinckney and an anonymous reviewer for criticizing preliminary drafts of the manuscript.

\section{LITERATURE CITED}

Andersen, R. A., Jacobson, D. M., Sexton, J. P. (1991). Provasoli-Guillard center for culture of marine phytoplankton: catalog of strains. Provasoli-Guillard Center for Culture of Marine Phytoplankton, West Boothbay Harbor, ME

Anderson, D. M., Galloway, S. B., Joseph, J. D. (1993). Marine biotoxins and harmful algae: a national plan. Woods Hole Oceanographic Institution Technical Report, WHOI-93-02, Woods Hole, MA

Bidigare, R. R., Kennicutt, M. C. 1l, Ondrusek, M. E., Keller, M. D., Guillard, R. R. L. (1990). Novel chlorophyll-related compounds in marine phytoplankton: distributions and geochemical implications. Energy Fuels 4: 653-657

Bidigare, R. R., Morrow, J. H., Kiefer, D. A. (1989). Derivative analysis of spectral absorption by photosynthetic pigments in the western Sargasso Sea. J. mar. Res. 47: 323-341

Bjørnland, T., Guillard, R. R. L., Liaaen-Jensen, S. (1988). Phaeocystis sp. clone 677-3 - a tropical marine planktonic prymnesiophyte with fucoxanthin and $19^{\prime}$-acyloxyfucoxanthins as chemosystematic carotenoid markers. Biochem. Syst. Ecol. 16: 445-452

Brunet, C., Brylinski, J. M., Lemoine, Y (1993). In situ variations of the xanthophylls diatoxanthin and diadinoxanthin photoadaption and relationships with a hydrodynamical system in the eastern English Channel. Mar. Ecol. Prog Ser 102: 69-77

Butler, W. L., Hopkins, D. W. (1970). An analysis of fourth derivative spectra. Photochem. Photobiol. 12: 451-456

Campbell, J. W., Yentsch, C. S., Esaias, W. E. (1986). Dynamics of phytoplankton patches on Nantucket Shoals: an experiment involving aircraft, ships and buoys. In: Bowman, J., Yentsch, C. M., Peterson, W. T. (eds.) Lecture notes on coastal and estuarine studies, Vol. 17: Tidal mixing and plankton dynamics. Springer-Verlag, Berlin, p. $140-163$

Carrick, H. J., Worth, D., Marshall, M. L. (1994). The influence of water circulation on chlorophyll-turbidity relationships in Lake Okeechobee as determined by remote sens. ing. J. Plankton Res. 16: 1117-1135

Cleveland, J. S., Weidemann, A. D. (1993). Quantifying absorption by aquatic particles: multiple scattering correction for glass-fiber filters. Limnol. Oceanogr. 38 1321-1327 
Demers, S., Roy, S., Gagnon, R, Vignault, C. (1991). Rapid light-induced changes in cell fluorescence and in xanthophyll-light cycle pigments of Alexandrium excavatum (Dinophyceae) and Thalassiosira pseudonana (Bacillariophyceae): a photo-protection mechanism. Mar. Ecol. Prog. Ser. 76: 185-193

Guillard, R. L. (1973). Division rates. In: Stein, J. R. (ed.) Handbook of phycological methods. Culture methods and growth measurements. University Press, New York, p. $289-312$

Guillard, R. R. L., Ryther, J. H. (1962). Studies of marine planktonic diatoms. I. Cyclotella nana Hustedt and Detonula confervacea (Cleve) Gran. Can. J. Microbiol. 8: 229-239

Hallegraeff, G. M. (1993). A review of harmful algal blooms and their apparent global increase. Phycologia 32: 79-99

Haxo, F. T (1985). Photosynthetic action spectrum of the coccolithophorid Emiliania huxleyi (Haptophyceae): 19 'hexanoylofucoxanthin as antenna pigment. J. Phycol. 21: $282-287$

Hooks, C. E., Bidigare, R. R., Keller, M. D., Guillard, R. R. L. (1988). Coccoid eukaryotic marine ultraplankters with four different HPLC pigment signatures. J. Phycol. 24: $571-580$

Jeffrey, S. W. (1976). The occurrence of chlorophyll $c_{1}$ and $c_{2}$ in algae. J. Phycol. 12: 349-354

Jeffrey, S. W., Sielicki, M., Haxo, F. T (1975). Chloroplast pigment patterns in dinoflagellates. J. Phycol. 11: 374-385

Johnsen, G., Nelson, N. B., Jovine, R. V. M., Prézelin, B. B. (1994a). Chromoprotein- and pigment-dependent modeling of spectral light absorption in two dinoflagellates, Prorocentrum minimum and Heterocapsa pygmaea. Mar. Ecol. Prog. Ser. 114: 245-258

Johnsen, G., Sakshaug, E. (1993). Bio-optical characteristics and photoadaptive responses in the toxic and bloom-forming dinoflagellates Gyrodinium aureolum. Gymnodinium galatheanum, and two strains of Prorocentrum minimum. J. Phycol. 29: 627-642

Johnsen, G., Sakshaug, E., Vernet, M. (1992). Pigment composition, spectral characterization and photosynthetic parameters in Chrysochromulina polylepsis. Mar. Ecol. Prog. Ser. 83: 241-249

Johnsen, G., Samset, O., Granskog, L., Sakshaug, E. (1994b). In vivo absorption characteristics in 10 classes of bloomforming phytoplankton: taxonomic characteristics and responses to photoadaption by means of discriminant and HPLC analysis. Mar. Ecol. Prog. Ser. 105: 149-157

Mantoura, R. F. C., Llewellyn, C. A. (1983). The rapid determination of algal chlorophyll and carotenoid pigments and their breakdown products in natural waters by reversephase high performance liquid chromatography. Analyt. Chim. Acta 151: 297-314

Millie, D. F., Baker, M. C., Tucker, C. S., Vinyard, B. T., Dionigi, C. P. (1992). High-resolution, airborne remotesensing of bloom-forming phytoplankton. J. Phycol. 28 : $281-290$

Millie, D. F., Baker, M. C. Vinyard, B. T., Tucker, C. S. (1995). Testing the temporal and spatial validity of site-specific models derived from airborne remote-sensing of phytoplankton. Can. J. Fish. Aquat. Sci. (in press)

Millie, D. F., Paerl, H. W., Hurley, J. P. (1993). Microalgal pigment assessments of high-performance liquid chromatography: a synopsis of organismal and ecological applications. Can. J. Fish. Aquat. Sci. 50: 2513-2527

Murphy, E. B., Steidinger, K. A., Roberts, B. S., Williams, J., Jolley, J. W. Jr (1975). An explanation for the Florida east coast Gymnodinium breve red tide of November 1972. Limnol. Oceanogr. 20: 481-486

Owens, T G., Gallagher, J. C., Alberte, R. S. (1987). Photosynthetic light-harvesting function of violaxanthin in Nannochloropsis (Eustigmatophyceae). J. Phycol. 23: $79-85$

Paerl, H. W. (1988). Nuisance phytoplankton blooms in coastal, estuarine, and inland waters. Limnol. Oceanogr. 33: $823-847$

Prezélin, B. B. (1976). The role of peridinin-chlorophyll aproteins in the photosynthetic light adaption of the marine dinoflagellate, Glenodinium sp. Planta (Berl.) 130: $225-233$

Richardson, L. L., Buisson, D., Liu, C-J., Ambrosia, V. (1994). The detection of algal photosynthetic pigments using airborne visible-infrared imaging spectrometer (AVIRIS) spectral data. Mar. Technol. Soc. J. 28: 10-21

Riley, C. M., Holt, S. A., Holt, G. J., Buskey, E. J., Arnold, C. R. (1989). Mortality of larval red drum (Sciaenops ocellatus) associated with a Ptychodiscus brevis red tide. Contrib. mar. Sci. 31. 137-146

Roesler, C. S., Perry, M. J., Carder, K. L. (1989). Modeling in situ phytoplankton absorption from total absorption spectra in productive inland marine waters. Limnol. Oceanogr. 34: $1510-1523$

Schofield, O., Bidigare, R. R., Prézelin, B. B. (1990). Spectral photosynthesis, quantum yield, and blue-green light enhancement of productivity rates in the diatom Chaetoceros gracile and the prymnesiophyte Emiliana huxleyi. Mar. Ecol. Prog. Ser. 64: 175-186.

Smith, C. M., Alberte, R. S. (1994). Characterization of in vivo absorption features of chlorophyte, phaeophyte, and rhodophyte algal species. Mar. Biol. 118: 511-521

Snedecor, G. W. Cochran, W G. (1980). Statistical methods, 7 th edn. Iowa State University Press, Ames

Steidinger, K. A. (1975). Implications of dinoflagellate life cycles on initiation of Gymnodinium breve red tides. Environ. Lett. 9: 129-139

Steidinger, K. A., Baden, D. G. (1984). Toxic marine dinoflagellates. In: Spector, D. L. (ed.) Dinoflagellates. Academic Press, Orlando, p. 201-261

Steidinger, K. A., Burklew, M. A., Ingle, R. M. (1973). The effects of Gymnodinium breve toxin on estuarine animals. In: Martine, D. F., Padilla, G. M. (eds.) Marine pharmacology: action of marine biotoxins at the cellular level. Academic Press, New York, p. 179-202

Steidinger, K. A., Ingle, R. M. (1972). Observations on the 1971 summer red tide in Tampa Bay, Florida. Environ. Lett. 3: 271-278

Tabachnick, B. G., Fidell, L. S. (1983). Using multivariate statistics. Harper and Row Publishers, New York

Tangen, K., Bjornland, T. (1981). Observation on pigments and morphology of Gyrodinium aureolum Hulbert, a marine dinoflagellate containing 19'-hexanoloxyfucoxanthin as the main carotenoid. J. Plankton Res. 3: $389-401$

Tester, P. A., Fowler, P. K., Turner, J. T (1989). Gulf Stream transport of the toxic red tide dinoflagellate, Ptychodiscus brevis, from Florida to North Carolina. In: Cosper, E. M., Bricelj, V. M., Carpenter, E. J. (eds.) Novel phytoplankton blooms: causes and impacts of recurrent brown tides and other unusual blooms. Springer-Verlag, Berlin, p. 349-358

Tester, P. A., Stumpf, R. P., Vukovich, F. M., Fowler, P. K., Turner, J. T (1991). An expatriate red tide bloom: transport, distribution, and persistence. Limnol. Oceanogr. 36 : 1053-1061 
Tyler, M. A., Stumpf, R. P. (1989). Feasibility of using satellites for detection of kinetics of small phytoplankton blooms in estuaries: tidal and migrational effects. Remote Sens. Environ. 27: 233-250

Wright, S. W., Jeffrey, S. W., Mantoura, R. F. C., Llewellyn, C. A., Bjørnland, T., Repeta, D., Welschmeyer, N. (1991).

This article was presented by G. W. Thayer (Senior Editorial Advisor), Beaufort, N. Carolina, USA
Improved HPLC method for the analysis of chlorophylls and carotenoids from phytoplankton. Mar. Ecol. Prog. Ser 77: $183-196$

Yentsch, C. S. (1962). Measurement of visible light absorption by particulate matter in the ocean. Limnol. Oceanogr 7 $207-217$

Manuscript first received: August 4, 1994

Revised version accepted: December 19, 1994 